\title{
Avaliação heurística de usabilidade em jornais online: estudo de caso em dois sites
}

Juan Miguel Rosa

\author{
Mestre em Administração pela UFRN. Professor do \\ SENAC-RN
}

Manoel Veras

\section{Doutor em Administração pela USP. Professor Associado da UFRN}

O trabalho foca a usabilidade em sites de jornais eletrônicos. São descritas as principais metodologias de avaliação de usabilidade propostas na literatura, e adotase, dentre elas, a avaliação heurística de Nielsen, para analisar a usabilidade dos sites dos jornais Estado de São Paulo e Folha de São Paulo. Uma vez detalhados os resultados das avaliações, apresentam-se as considerações finais, nas quais destacam-se a concentração de violações nas heurísticas sobre visibilidade do estado do sistema; a consistência e padrões; e a prevenção de erros.

Palavras-chave: Usabilidade; Imprensa online; Jornal eletrônico; Avaliação heurística.

\section{Usability heuristic evaluation in online journals: case study in two websites}

The paper focuses usability in news websites. The text describes main usability evaluation methodologies proposed by scientific literature, among which Nielsen's heuristic evaluation is adopted for the analysis of the sites of Estado de São Paulo and Folha de São Paulo journals. Evaluation results are fully displayed before final considerations stress the concentration of usability violations in heuristics related to visibility of system status; consistency and standards; and error prevention. 
Keywords: Usability; Online news; Electronic journal; Heuristic evaluation.

Recebido 18.01.2011 Aceito em 08.02.2013

\section{Introdução}

Quarenta anos depois que a ARPANET, embrião da Internet, fizesse possível a primeira conexão entre dois computadores ${ }^{1}$, a World Wide Web reina indiscutivelmente como a mídia de mais rápido crescimento na história (EIGHMEY; McCORD, 1998). Calcula-se que, atualmente, hospede mais de 206 milhões de Websites ${ }^{2}$ e conte com mais de 1.730 milhões de usuários no mundo ${ }^{3}$. Pode-se afirmar que a World Wide Web é, hoje, o maior repositório de dados do mundo, que conta com o maior número de visitantes à procura de informações (HERRERA-VIEDMA et al., 2006), uma constatação que fala por si só da relevância da Internet como canal de comunicação e consulta de informação entre particulares e organismos públicos e privados, de todos os setores.

Confrontadas com um espaço virtual de comunicação que, a essas características singulares de extensão e abrangência, acrescenta um caráter manifestamente dinâmico (LAWRENCE; GILES, 1999), aquelas instituições que, pela sua atividade, precisam não só estar presentes na rede, como atrair e manter uma massa crítica de usuários, deparam-se com um desafio de grandes proporções. É o caso, dentre muitas outras, das empresas de comunicação em geral e de conteúdos informativos em particular. A multiplicação tanto de produtos de informação jornalística online quanto de recursos que permitem aos usuários gerar e distribuir rapidamente conteúdos informativos através da rede - blogs, podcasts, redes sociais, etc. - , unido ao declínio continuado do número de leitores de jornais em papel e dos ingressos gerados por esses produtos ${ }^{4}$, tem levantado dúvidas sobre o futuro do jornalismo tradicional e, muito especialmente, sobre a sobrevivência a médio e longo prazo da mídia impressa.

Há muito que as empresas tradicionais de produção de notícias começaram a dirigir sua atenção para a Internet, como novo cenário de atuação, em um processo que as levaria à criação de versões eletrônicas dos seus produtos impressos. Os primeiros jornais online foram se aperfeiçoando até ganhar personalidade própria e contornos bem definidos, depois de alguns passos iniciais titubeantes. Durante o longo percurso da mídia eletrônica, que podemos considerar iniciado - bem que de forma embrionária - com os primeiros videotextos da BBC e o primeiro banco de informações do New York Times, ambas as experiências datadas

\footnotetext{
${ }^{1}$ A Brief History of the Internet (LEINER et al., 2003).

${ }^{2}$ Segundo pesquisa conduzida pela empresa Netcraft, em janeiro de 2010.

${ }^{3}$ Dados de Internet World Stats (Disponível em: <www.internetworldstats.com>. Acesso em: 27 jul. 2009), correspondentes a setembro de 2009.

${ }^{4}$ Conforme dados do relatório The State of the News Media (Disponível em: <www.stateofthemedia.org>. Acesso em: 27 jul. 2009).
} 
em $1969^{5}$, as empresas jornalísticas desenvolveram uma categoria de produto completamente nova - o jornal online - orientada a um usuário final que ia desenvolvendo, em um rápido processo de aprendizado, novas formas de relacionamento com a informação, nem sempre condizentes com a tradicional unidirecionalidade da relação entre o jornalista e o consumidor de notícias. Conforme descrito por Pryor (2002), os grandes grupos tradicionais de comunicação só apostaram firmemente em produtos eletrônicos, a partir dos primeiros anos da década de 90, de forma que esse novo modelo de negócio tem apenas duas décadas de existência efetiva.

Como consequência dessa rápida evolução, em paralelo da imprensa online, como novo produto jornalístico e do usuário da Internet como o seu consumidor potencial, deparamo-nos, hoje, com um complexo panorama em que se carece, pela própria natureza dinâmica da Internet, como fenômeno de comunicação, de um marco teórico tão sólido quanto seria desejável para guiar as decisões das empresas de comunicação a respeito dos seus produtos para a Internet. Em um cenário tal, a aplicação, à mídia eletrônica, de métricas validadas para analisar a usabilidade de Websites, adquire relevância fundamental, considerando que uma maior usabilidade da interface computador-usuário aumenta as possibilidades dos utilizadores passarem a visitar regularmente um site (WINCKLER; PIMENTA, 2002). O contrário, logicamente, também é verdadeiro: quanto menor a usabilidade, menores as chances de se fidelizar o usuário.

Depois de uma revisão da literatura sobre o conceito de usabilidade aplicado a sites da Internet e especificamente sobre as modalidades de avaliação propostas por diferentes autores, o presente estudo analisa a usabilidade das versões online de dois dos principais jornais brasileiros ${ }^{6}$, com o objetivo de detectar neles, aspectos que, sob esse prisma, possam ser considerados como passíveis de melhora. Paralelamente, o artigo se propõe a identificar, nos casos estudados, problemáticas comuns de usabilidade que possam apontar a necessidade de uma atenção especial, durante as etapas de desenvolvimento de produtos jornalísticos para a Internet.

Visando a atingir esses objetivos, foi adotada, dentre as propostas metodológicas disponíveis no campo de estudos da usabilidade, a avaliação heurística (NIELSEN; MOLICH, 1990; NIELSEN, 1994), que é um processo que permite localizar problemas de usabilidade em interfaces computador-usuário, mediante a análise da sua adequação a uma série de princípios pré-estabelecidos, conhecidos como heurísticas. Os princípios, aqui adotados, são as dez heurísticas desenvolvidas por Nielsen (1994) e os jornais eletrônicos selecionados para a análise foram o Estado de São Paulo e a Folha de São Paulo. Uma vez apresentado o estudo de caso de cada um desses jornais online - que foram selecionados pela sua relevância e tradição dentro do jornalismo brasileiro e pela elevada

\footnotetext{
${ }^{5}$ Fonte: New Media Timeline (1969-2008), de David Shedden. Disponível em: <www.poynter.org>. Acesso em: 27 jul 2009).

${ }^{6}$ Dados de circulação feitos públicos em abril de 2009, pela Associação Nacional de Jornais (ANJ).
} 
circulação das suas versões impressas -, são colocadas as considerações finais e apontadas tanto as limitações encontradas pelo estudo quanto algumas propostas para futuras linhas de pesquisa sobre o assunto tratado.

\section{Conceito de usabilidade}

A usabilidade é uma ideia central na literatura sobre HumanComputer Interaction (HCI) ou interação computador-usuário (LECEROF; PATERNÒ, 1998; AGARWAL; VENKATESH, 2002). A primeira norma que definiu o conceito de usabilidade foi a ISO/IEC 9126, de 1991, sobre qualidade de software, que considera a usabilidade como "um conjunto de atributos de software relacionado ao esforço necessário para seu uso e para o julgamento individual de tal uso por determinado conjunto de usuários" (DIAS, 2003, p. 3). Em 1998, a norma ISO 9241-11 Guidance on Usability, definiu usabilidade como "a capacidade de um produto ser usado por usuários específicos para atingir objetivos específicos com eficácia, eficiência e satisfação em um contexto específico de uso" (DIAS, 2003, p. 4).

Outros critérios têm enriquecido, ao longo do tempo, o conceito de usabilidade. Nielsen $(1993 ; 1995)$ apud Carvalho (2002) aponta cinco parâmetros para a avaliação da usabilidade. São eles: fácil de aprender (o usuário consegue interagir rapidamente com o sistema); eficiente para usar (uma vez aprendido o funcionamento do sistema, o usuário consegue localizar a informação desejada); fácil de lembrar (o aprendizado do funcionamento não precisa ser feito novamente a cada interação com o sistema, mesmo para usuários ocasionais); pouco sujeito a erros (os usuários não têm perigo de cometer erros graves durante a utilização do sistema e têm a possibilidade de desfazer os que cometem); e agradável de usar (os usuários gostam de interagir com o sistema e se sentem satisfeitos com ele).

Nessa mesma direção, Lecerof e Paternò (1998) consideram noções, como relevância, entendida como o grau em que o sistema analisado serve às necessidades dos usuários; facilidade de aprendizagem ou o grau de facilidade com que o funcionamento do sistema pode ser inicialmente aprendido e posteriormente lembrado pelos usuários; e segurança, que, para esses autores, passa por dar ao usuário a possibilidade de desfazer as suas próprias ações durante a interação com o sistema e impedir que o mesmo atue em forma "destrutiva". Um resumo adequado do conceito de usabilidade é o proposto por Smith e Mayes (1996) apud Carvalho (2002). Para eles, a usabilidade descansa em três pilares fundamentais: facilidade de aprendizagem; facilidade de utilização; e satisfação no uso do sistema pelo utilizador.

\section{Métodos de avaliação da usabilidade}

As abordagens propostas, na literatura, sobre interação computador-usuário, para avaliar o grau de usabilidade de um sistema 
são diversas. Mas todas elas visam ao mesmo objetivo, resumido, assim, por Dias (2003, pág 7).

A avaliação da usabilidade de um sistema interativo deve verificar o desempenho (eficácia e eficiência) da interação homem-computador e obter indícios do nível de satisfação do usuário, identificando problemas de usabilidade durante a realização de tarefas específicas em seu contexto de uso. Um problema de usabilidade pode ser definido como qualquer característica, observada em determinada situação, que possa retardar, prejudicar ou inviabilizar a realização de uma tarefa, aborrecendo, constrangendo ou traumatizando o usuário.

Os métodos de avaliação da usabilidade podem ser classificados em três grandes grupos, conforme a sua natureza: métodos de inspeção, métodos de teste com usuários e métodos baseados em modelos (DIAS, 2003). Gray e Salzman (1998), por sua vez, propõem uma classificação das metodologias de avaliação em duas grandes categorias: analíticas, na qual estaria incluída a avaliação heurística, além de outros métodos de inspeção; e empíricas, que incluiriam todos os métodos, envolvendo testes com usuários. O presente estudo adota a classificação proposta por Dias, apresentando, em primeiro lugar e de forma sucinta, os métodos de teste com usuários e aqueles baseados em modelos, para depois focar a atenção nos métodos de inspeção, destacando, dentre eles, a avaliação heurística.

a) métodos de teste com usuários: caracterizados pela participação direta dos usuários do sistema na avaliação, os métodos de testes com usuários podem ser prospectivos, servindo-se, nesse caso, de questionários e entrevistas para capturar as opiniões e experiências dos usuários, ou empíricos - também conhecidos como ensaios de interação -, adotando, nesse caso, técnicas de observação do uso dos sistemas em situações reais (DIAS, 2003);

b) métodos baseados em modelos: os métodos baseados em modelos procuram aferir o grau de usabilidade de um sistema, a partir de modelos da sua interface e/ou de seus usuários (DIAS, 2003), isto é, de representações que capturam e modelam a forma em que os usuários interagem com o sistema. Dias destaca, dentro dessa categoria, a família Goals, Operators, Methods and Selection Rules (GOMS) ${ }^{7}$, proposta por Card, Moran e Newell, em 1983, que combina diferentes técnicas de modelagem e análise de tarefas em termos de objetivos (os resultados específicos que o usuário deseja conseguir através das suas ações), operadores (as ações que devem ser executadas para alcançar o objetivo proposto),

\footnotetext{
${ }^{7}$ Disponível em: <http://en.wikipedia.org/wiki/GOMS>. Acesso em: 29 jul. 2009.
} 
métodos (sequências de operadores que levam à consecução de um objetivo geral) e regras de seleção (critérios para a escolha de um entre diversos métodos quando há mais de uma opção para realizar uma ação); e

c) métodos de inspeção: avaliação heurística: os métodos de inspeção, descritos formalmente pela primeira vez em 1990 (NIELSEN; MOLICH，1990; NIELSEN, 1995), baseiam-se no exame de usabilidade realizado por especialistas. Os avaliadores, segundo Nielsen, podem ser especialistas em usabilidade, consultores de desenvolvimento de software, usuários finais com conhecimento especializado ou outros profissionais, e a qualidade da avaliação repousa, em último termo, no seu julgamento.

A avaliação heurística, conforme descrita por Nielsen (1994), consiste no exame pormenorizado de uma interface de usuário realizado por especialistas, com o objetivo de avaliar a sua adequação a uma série de princípios de usabilidade reconhecidos, as heurísticas. $O$ autor recomenda que a avaliação seja aplicada por vários indivíduos de forma isolada, para garantir a independência das diferentes avaliações e evitar a ocorrência de vieses, como consequência da interação entre os avaliadores. Mesmo que essa modalidade de avaliação possa ser conduzida por um único indivíduo, a sua efetividade aumenta com o número de avaliadores.

Como resultado das avaliações, podem ser gerados relatórios escritos - o que apresenta a vantagem de se ter um registro formal do processo, mas exige a participação de um coordenador, para compilar as avaliações dos diferentes especialistas - ou podem ser feitas verbalizações pelos avaliadores durante a interação com o sistema, que serão recolhidas por um observador. Nesse caso, Nielsen salienta que o observador, diferentemente do que ocorre nos testes com usuários, não tem a missão de interpretar os comentários dos avaliadores, devendo limitar-se a registrá-los. Com independência do formato escolhido, o resultado gerado pela avaliação heurística será sempre uma lista de problemas de usabilidade na interface, referentes a princípios de usabilidade que, conforme o julgamento do avaliador, são violados no seu design atual (NIELSEN, 1994).

Uma avaliação heurística típica consome entre uma e duas horas (NIELSEN, 1994), se bem que pode ser necessária uma maior duração em cujo caso a avaliação deverá ser dividida em diferentes sessões - ao se avaliar interfaces de alta complexidade, como é o caso dos jornais eletrônicos aqui analisados. O avaliador pode decidir a forma pela qual irá proceder na avaliação, mas a recomendação geral - que foi seguida no presente estudo - é interagir pelo menos duas vezes com o sistema: o primeiro contato permite capturar o fluxo geral da navegação e o escopo macro da interface; e a segunda interação foca elementos específicos do 
sistema. A comparação do sistema avaliado com as heurísticas prédeterminadas, é a base da metodologia heurística, mas o avaliador tem liberdade, durante o processo, para considerar outros princípios de usabilidade que julgue relevantes no sistema estudado.

Em função do seu maior ou menor impacto sobre a interação do usuário com o sistema, os problemas de usabilidade podem ser classificados como barreiras (quando não podem ser superados pelo usuário); obstáculos (o usuário pode aprender a superar o problema, mas, até lá, o desempenho da sua interação com o sistema fica comprometido); e ruídos, problemas estes últimos, de menor impacto, por causarem uma diminuição do desempenho menos significativa (Dias, 2003).

\section{As 10 heurísticas de Nielsen}

Adotando a avaliação heurística de usabilidade, o presente estudo examinou os dois casos selecionados sob o prisma das heurísticas de Nielsen, desenvolvidas originalmente por esse autor, em colaboração com Molich (NIELSEN; MOLICH, 1990) e condensadas, posteriormente, por Nielsen, nas dez recomendações apresentadas abaixo (NIELSEN, 1994, tradução nossa):

visibilidade do estado do sistema: o sistema deve manter os usuários informados do que está acontecendo a cada momento, através de feedback apropriado, em tempo razoável;

correspondência entre o sistema e o mundo real: o sistema deve falar a linguagem do usuário, com palavras, frases e conceitos que sejam familiares para ele, em lugar de termos técnicos orientados ao próprio sistema. Devem ser seguidas convenções do mundo real, de maneira que a informação seja oferecida em uma ordem lógica e natural;

liberdade e controle por parte do usuário: com alguma frequência, os usuários escolhem funções do sistema por engano, motivo pelo qual thes deve ser oferecida uma "saída de emergência", claramente sinalizada, para que possam sair do estado indesejado, sem a necessidade de diálogos extensos. Deve ser facilitada a opção de desfazer e refazer ações;

consistência e padrões: devem ser seguidas convenções para que os usuários não tenham que se perguntar se determinadas palavras, situações ou ações significam, de fato, a mesma coisa;

prevenção de erros: preferível a ter boas mensagens de erro é ter um design que evite a ocorrência de problemas. O sistema deve eliminar as condições que possam levar a falhas ou 
apresentar ao usuário opções de confirmação, antes dele executar determinadas ações;

reconhecimento preferível à memorização: o sistema deve minimizar a quantidade de informação que o usuário precisará lembrar para usá-lo, fazendo com que objetos, ações e opções sejam visíveis. O usuário não deve precisar lembrar informações de uma parte de um diálogo a outra. As instruções de uso do sistema devem ser visíveis ou facilmente recuperáveis, sempre que necessário;

flexibilidade e eficiência de uso: os aceleradores, invisíveis para o usuário inexperiente, podem agilizar a interação para o usuário experiente, de forma que o sistema possa atender aos dois perfis de utilizadores. Os usuários devem ter a opção de personalizar ações frequentes;

design estético e minimalista: os diálogos não devem conter informações irrelevantes ou muito raramente requisitadas. Cada unidade extra de informação, em um diálogo, concorre com as unidades de informação relevantes e diminui a sua visibilidade;

ajuda aos usuários para reconhecer, diagnosticar e se recuperar dos erros: as mensagens de erro devem ser expressas em linguagem compreensível (sem códigos), indicando, com precisão, o problema e sugerindo uma solução de forma construtiva; e

suporte e documentação: é preferível que o sistema possa ser usado sem documentação, mas pode resultar necessário fornecer suporte e documentação ao usuário. Essas informações devem ser de extensão reduzida, fáceis de localizar e focadas na tarefa, apresentando uma lista das ações específicas que o usuário deverá executar.

\section{Estudos de caso}

Apresentam-se, a seguir, os resultados das duas avaliações de usabilidade realizadas para o presente estudo, sobre as versões eletrônicas dos jornais Estado de São Paulo e Folha de São Paulo, conduzidas entre os dias 27 de julho e 1 de agosto de 2009. Cada um dos sites analisados requereu duas sessões de avaliação. A primeira de aproximadamente uma hora de duração e a segunda superior a duas horas, conduzidas por um único avaliador. Seguindo a metodologia proposta por Nielsen (1994), para a execução de avaliações heurísticas, não são apresentadas valorações gerais sobre a usabilidade dos sites analisados e, sim, duas listas independentes, que registram e descrevem detalhadamente as violações das heurísticas detectadas em cada um deles. As violações são classificadas como barreiras, obstáculos ou ruídos, 
em função do seu impacto sobre a interação do usuário com o sistema, conforme a categorização proposta por Dias (2003).

\subsection{Estado de São Paulo}

O primeiro site avaliado foi o do jornal Estado de São Paulo ${ }^{8}$, com os seguintes resultados:

Heurística 1 - Visibilidade do estado do sistema

violação 1.1 (barreira) - a seção de opinião dá acesso a um fórum dos leitores, no qual o usuário (que, muito provavelmente, se considera leitor) não encontra forma alguma de participar, nem explicação de porque está impedido de fazê-lo. Pode-se presumir que o motivo seja o fato de o usuário não ser assinante da edição impressa do diário, mas o sistema não fornece nenhuma informação nesse sentido;

violação 1.2 (obstáculo) - a seção "Direto da Fonte", dentro do Caderno 2, não permite, diferentemente das outras seções, a identificação rápida pelo usuário do tipo de conteúdos oferecidos nela. Também, não há indicações formais que permitam, de forma intuitiva, descobrir como pode ser feita a navegação, através dos seus conteúdos;

violação 1.3 (obstáculo) - quando um usuário não assinante do diário impresso tenta acessar a versão digitalizada do mesmo (não o jornal online, que é de livre acesso), aparece uma janela de diálogo, informando que o serviço é exclusivo para assinantes e oferecendo a possibilidade de assinar a edição impressa do produto. Mas, quando o usuário fecha essa janela para voltar à navegação anterior, depara-se com outra página, diferente daquela que estava consultando previamente. Essa página propõe um link alternativo: "caso não esteja visualizando a versão digital dessa publicação". Clicando nesse link alternativo, o usuário volta à janela de diálogo supracitada, de acesso ao diário digital exclusivo para assinantes, em um giro desnecessário. Caso ele perceba que a ação por ele desejada - voltar à página prévia de navegação só poderá ser efetivada com o botão "atrás" do navegador, e, assim, conseguirá completar a tarefa, mas com um passo redundante e desprovido de finalidade, dado que o motivo pelo qual o usuário não conseguiu visualizar o diário digital não se relacionava a questões técnicas e, sim, às permissões de acesso;

${ }^{8}$ Disponível em: <www.estadao.com.br>. Acesso em: 28 jul. 2009. 
violação 1.4 (obstáculo) - ao realizar o cadastro gratuito no site, aparece uma página com a seguinte mensagem, que reproduzimos com erros ortográficos incluídos:

"Parábens, (nome do usuário) seu email: endereço@estadao.com.br foi cadastrado corretamente, aguarde um instante para criarmos sua caixa postal.

Agora você pode desfrutar de uma caixa postal na Internet, mais uma interface web para acessar seus emails, com a qualidade Estadão.

Você estara recebendo um email de boas vindas, nele ira encontrar as instruções para configurar o seu Outlook Express e link uteis.

Atenciosamente,

Equipe Webmail"

Pelo teor e conteúdo da mensagem - e especialmente pela indicação de "aguardar um instante" -, o usuário é levado a pensar que, para completar com sucesso a tarefa, deverá esperar sem executar nenhuma outra ação. Em casos assim, é habitual incorporar algum tipo de recurso - um dos mais usados é a barra de estado - que informe ao usuário o tempo restante estimado para a finalização da tarefa e lhe transmita a certeza de que alguma ação está acontecendo, enquanto ele aguarda. Não aparece recurso algum e foi comprovado que não era necessário o usuário esperar, dado que a tarefa tinha sido completada corretamente. O usuário pode ser, assim, levado ao engano, sobre o grau em que a tarefa foi completada e sobre o que deverá fazer a seguir; e

violação 1.5 (barreira) - na tarefa de subscrição ao serviço de feeds em formato RSS, é apresentada uma lista de passos a seguir que, dependendo do navegador utilizado, nem sempre corresponde à realidade: enquanto o navegador Mozilla Firefox oferece as opções efetivamente anunciadas pelo site, 0 Internet Explorer oferece um caminho totalmente diferente para completar a tarefa.

Heurística 2 - Correspondência entre o sistema e o mundo real

violação 2.1 (obstáculo) - no menu principal da página de início, a seção "Primeira página" não dá acesso, como as outras, a um submenu próprio de subseções incluídas nela, e, sim, a duas seções independentes ("Últimas noticias" e "Tags"), que não guardam relação de ordenação hierárquica de conteúdos com a seção de primeira página, contradizendo, assim, os padrões habituais conhecidos pelo usuário de imprensa online, respeitados no restante de seções. 
Heurística 4 - Consistência e padrões

violação 4.1 (obstáculo) - os títulos das seções gerais do diário (Nacional, Internacional, Economia, Esportes, etc.) são os únicos links encontrados no site que, ao se passar o mouse sobre eles, não são sinalizados claramente como links através de sublinhado ou mudança perceptível de cor e/ou formato. Dado que todos esses títulos abrem submenus de seções internas, alguns usuários podem não identificar, com rapidez, que eles mesmos, se selecionados, levam à página geral da seção. Nesses casos, os usuários se limitarão a visitar as subseções até descobrirem, acidentalmente, o seu engano. Supõe-se que a falta de efeito de sublinhado nesses links obedeça a critérios estéticos, dada a sua localização na parte nobre da Home Page, mas o resultado é uma inconsistência formal com o resto de links do site;

violação 4.2 (ruído) - quando é acessado o especial "Megacidades", a cabeceira principal de navegação muda não só o layout, como a oferta de links para navegação, sem motivo aparente e sem que essa ocorrência tenha sido identificada em nenhum outro ponto do site (não foram consideradas como violações as mudanças de layout da mesma cabeceira no caso dos suplementos "Link" e "Paladar", porque, nesses casos, a mudança foi percebida como necessária, a fim de acomodar na página, a imagem corporativa diferenciada desses dois produtos independentes);

violação 4.3 (obstáculo) - a seção "Direto da Fonte", dentro do Caderno 2, inclui, na sua navegação interna, o link "Notas", que direciona ao blog da seção. Esse blog difere tanto no layout quanto nas opções de navegação que oferece, do padrão apresentado por todos os demais blogs observados no site, além de não ser identificado como tal em nenhum momento; e

violação 4.4 (obstáculo) - foram detectados vários casos de links que, pelos seus layout e redação, sugerem estar direcionados ou a uma notícia específica ou a conteúdos especiais, mas levam o usuário a uma lista de tags sobre o assunto tratado no link.

\section{Heurística 5 - Prevenção de erros}

violação 5.1 (obstáculo) - as tags oferecidas, na primeira página, apresentam problemas de visualização das letras com til e acento nos dois navegadores utilizados durante a avaliação (Firefox e Explorer); 
violação 5.2 (barreira) - em toda página dedicada a uma notícia específica, é oferecido um link à lista geral de tags, que abre uma caixa vazia;

violação 5.3 (ruído) - quando uma notícia não recebeu ainda nenhum comentário dos leitores, o link que permite ler todos os comentários continua ativado, mas direciona para uma página que poder-se-ia descrever como a versão beta - pela aparência de inacabada - da página "Comente também". Selecionando o único link ativo dessa página, o usuário acessa a página conhecida como "Comente também", tendo dado um passo desnecessário, que seria eliminado pelo simples procedimento de manter desativado o link, enquanto não há comentário algum a ler;

violação 5.4 (ruído) - quando uma notícia não recebeu ainda nenhum comentário dos leitores, o título "Comentários" (que, no caso contrário, não reage como link ativo) reage como link, mas, se clicado, não executa ação alguma;

violação 5.5 (barreira) - em todos os blogs visitados, é oferecido, imediatamente depois do título de cada entrada, um ou, por vezes, vários links sob a epígrafe de "seção", em palavras relacionadas com o tema do blog, o que leva a pensar em uma seção de assuntos relacionados a ele. Porém, ao clicar em qualquer um desses links, a única coisa que ocorre é um mero reload da página; e

violação 5.6 (obstáculo) - no "Portal do assinante", existe um link com o mesmo nome que, se selecionado, não carrega página alguma, independente do navegador utilizado, conduzindo o usuário a uma página em branco e interrompendo momentaneamente a navegação.

\section{Heurística 8 - Design estético e minimalista}

violação 8.1 (obstáculo) - a disposição dos elementos que compõem a página inicial do site dedicado ao "Mídia Kit", acessível através do link "Como anunciar", não propõe nenhuma rota de navegação intuitiva, dificultando a localização rápida das informações mais relevantes sobre a veiculação de publicidade dos produtos do Grupo Estado, objetivo que supõe-se como principal do usuário desse site específico. Um dos problemas é a junção formal de um banner corporativo, que parece ser o menu central de navegação do site. Também não ajuda a navegação do usuário inexperiente, o fato do o primeiro link oferecido nesse menu principal gerar uma mensagem de "Página de acesso restrito" (acessível unicamente para usuários cadastrados). E surpreende, muito especialmente, que o acesso a uma ferramenta de extrema 
utilidade para o usuário potencial desse espaço (um site independente e de navegação muito intuitiva, com informação detalhada sobre todas as opções de anúncios classificados do jornal) fique oculto por trás de um banner, que não permite identificar, com claridade, a relevância do conteúdo e do que pode ser acessado através dele. Um conteúdo que, vale salientar, pode ser acessado unicamente através desse banner.

As violações 1.1, 1.5, 5.2 e 5.5 foram consideradas barreiras à interação do usuário com o sistema, porque ou bem impediram a realização de uma ação desejada pelo usuário (no caso da violação 1.5, ele poderia desistir de completar a tarefa, por acreditar que há impedimentos técnicos insuperáveis) ou bem criaram a expectativa de realização de uma determinada tarefa para de imediato impossibilitar a sua execução, caso das violações 1.1 e 5.5. As violações 1.2, 1.3, 1.4, $2.1,4.1,4.3,4.4,5.1,5.6$ e 8.1 foram consideradas obstáculos, dado que, mesmo dificultando a interação ou desviando momentaneamente o usuário dos seus objetivos, não impediram a execução das ações desejadas por ele. Já as violações 4.2, 5.3 e 5.4 foram consideradas meros ruídos, pelo seu escasso impacto no desenvolvimento da interação. Não foi identificada, nesse primeiro caso analisado, nenhuma violação das heurísticas 3, 6, 7, 9 e 10 .

\subsection{Folha de São Paulo}

O segundo site avaliado foi o do jornal Folha de São Paulo ${ }^{9}$, com os seguintes resultados:

Heurística 1 - Visibilidade do estado do sistema

violação 1.1 (barreira) - Na página inicial do site específico, que apresenta as opções de inserção publicitária em produtos do Grupo Folha ("Publicidade Folha"), aparecem os links "Enviar Reservas" e "Enviar Material", que permitem, conforme descrito na própria página, reservar espaços publicitários e encaminhar ao jornal material digital para anúncios. Quando o usuário tenta utilizar um desses links, aparece a mensagem reproduzida abaixo:

\footnotetext{
${ }^{9}$ Disponível em: <www.folha.uol.com.br>. Acesso em: 28 jul. 2009.
} 


\begin{tabular}{|c|}
\hline ATENÇÃO! \\
\hline $\begin{array}{c}\text { Acesso permitido apenas para Agências, Representações, Corretores e Gráficas cadastradas } \\
\text { na Folha. Para maiores informações, favor entrar em contato com o departamento de } \\
\text { Cadastro ou Inserção Digital. }\end{array}$ \\
\hline Retornar \\
\hline
\end{tabular}

Aqueles usuários que partilham de conhecimentos básicos sobre o funcionamento do departamento de publicidade de uma empresa jornalística, sabem que a reserva de espaços publicitários e o envio de materiais não é feito geralmente pelo anunciante final e, sim por um dos intermediários citados na mensagem. Mas o usuário médio, desconhecedor da cadeia que leva às inserções de publicidade na mídia, pode facilmente ser levado à conclusão - errônea, mas em nada absurda - de que esses links lhe permitirão, se for o seu interesse, como pessoa física ou jurídica, reservar espaços publicitários em produtos do Grupo Folha e remeter à equipe de diagramadores os seus materiais de publicidade. Esse usuário só descobre o erro ao que foi induzido quando tenta usar um desses links. Considera-se que existe, nesse ponto, uma falha de suporte ao usuário médio, que deveria ser informado antecipadamente - isto é, na própria página na qual aparecem os links de que essas opções de interação com o departamento de publicidade do grupo estão reservadas a agências, representações, corretores e gráficas cadastradas na Folha.

violação 1.2 (obstáculo) - durante a navegação pelos conteúdos sobre inserção de publicidade em produtos do Grupo Folha, o link "Perguntas Frequentes" não direciona, como seria esperado, a um menu de FAQ's, que responda a possíveis dúvidas de usuários pouco familiarizados com o sistema e, sim, a uma página com telefones e e-mails de contato de diferentes departamentos relacionados com o setor de publicidade. Unicamente se o usuário tiver a iniciativa de usar a scrollbar vertical dessa página, encontrará o espaço "Dúvidas Técnicas", no qual são apresentadas informações que, pela linguagem fortemente técnica, não orienta usuários inexperientes - como levaria a pensar o uso da expressão "Perguntas frequentes" -, senão a usuários muito familiarizados com os procedimentos para inserção de anúncios; e

violação 1.3 (obstáculo) - na página inicial do site "Livraria da Folha", foi observada uma localização deficiente de informações relevantes para o usuário pouco familiarizado com 
esse serviço, como são "Quem somos", "Política de Segurança" e "Dúvidas frequentes". Os links a esses três assuntos estão disponíveis unicamente no extremo inferior de uma página saturada de conteúdos, ficando ocultos durante a maior parte da navegação. Só com o uso da scrollbar vertical podem ser visualizados.

\section{Heurística 2 - Correspondência entre o sistema e o mundo real}

violação 2.1 (obstáculo) - o menu principal de navegação apresenta as seções do jornal em ordem alfabética, de forma que seções de conteúdos tradicionalmente considerados leves - como "Ambiente", "Bichos" ou "Comida" - aparecem no quadrante superior esquerdo da página, enquanto os links das seções de conteúdos de maior peso específico, como as notícias de âmbito internacional - contidas na seção "Mundo", aparecem em localização menos privilegiada, no quadrante superior direito da página. A tradição de ordenar as seções de um produto jornalístico em função da sua relevância informativa é forte o suficiente, em mídia impressa e online, para que essa aplicação do critério alfabético possa se considerar uma violação da correspondência do sistema com o mundo real do usuário; e

violação 2.2 (barreira) - embaixo do texto de boa parte das notícias consultadas, é oferecida, sob a epígrafe "Especial", a possibilidade de ler mais sobre o assunto ali tratado. Quando selecionada essa opção, apresenta-se ao usuário uma nova página com a lista dos resultados de uma busca automática sobre a palavra-chave da notícia em questão. O resultado da ação corresponde com o que foi oferecido ao usuário: acessar maiores informações sobre um determinado assunto. Considera-se, porém, inadequado o uso da palavra "Especial", dado que no jargão do jornalismo - compartilhado pelo público leitor -, esse termo define produtos diferenciados, com informações aprofundadas e, em ocasiões, formato e design próprios, e é assim que o termo vem sendo utilizado pela maioria dos jornais online (inclusive a própria Folha, que, em outro ponto do site, apresenta, sob a epígrafe "Especial", uma seção completa com reportagens em profundidade sobre os assuntos mais diversos). Pode-se, portanto, afirmar que muitos usuários da Folha Online se sentirão, no mínimo, decepcionados, ao comprovar que, por trás da palavra "Especial", oferecida na conclusão de muitas notícias, o que se oculta é uma miscelânea de informações nos formatos mais diversos, ordenadas apenas cronologicamente. 
Heurística 3 - Liberdade e controle por parte do usuário

violação 3.1 (ruído) - durante o período em que foi conduzida a avaliação, um dos banners publicitários contidos no site ampliava o seu tamanho ao se passar o mouse nele. Pela sua colocação em algumas das páginas, usuários não interessados no banner veriam o seu tamanho ampliado, ao tentar acessar determinadas informações situadas nas proximidades, dificultando levemente a navegação. Vale salientar que, diferentemente do que foi observado em outros recursos de publicidade no Website da Folha, o referido banner não podia ser fechado pelo usuário.

Heurística 4 - Consistência e padrões

violação 4.1 (ruído) - na conclusão do texto da maioria das notícias, oferecem-se listas de links a conteúdos diretamente relacionados com o assunto da notícia. No entanto, em algumas notícias, essa lista inclui links a conteúdos sem relação alguma com o assunto da notícia, sem que possa se identificar qual é o critério aplicado para a seleção desses outros links;

violação 4.2 (obstáculo) - foram detectados vários casos em que links a blogs do site são identificados sob a epígrafe "Colunistas". Levando em consideração que o site conta com contribuições tanto de colunistas quanto de blogueiros e diferencia claramente entre esses dois tipos de conteúdos de opinião, a identificação de um link a um blog com a palavra "Colunistas" só pode ser considerada uma inconsistência nos padrões de identificação dos conteúdos do site;

violação 4.3 (ruído) - as listas das cinco notícias "+ lidas", "+ curiosas" e "+ enviadas" são apresentadas em um menu conjunto e com idêntico formato e, também, as listas de notícias são automaticamente atualizadas em função da seção que está sendo consultada pelo usuário. Porém, essa atualização só acontece nos casos das notícias mais lidas e das mais enviadas, sendo que a lista das notícias mais curiosas permanece inalterada, independente da seção; e

violação 4.4 (obstáculo) - no apartado "Fale conosco", são oferecidos, com idêntico formato, dois links: um "para apontar erros e sugerir correções na Folha Online" e outro "para apontar erros e sugerir correções na Folha de S.Paulo". Mas, enquanto o primeiro conduz a uma janela de diálogo claramente direcionada à redação e envio de mensagens pelo usuário, a segunda conduz a uma página na qual é apresentada a figura do ombudsman do jornal, sendo necessários mais dois passos - dentre eles, a utilização do 
programa Outlook - para que o usuário possa efetivamente completar a tarefa desejada.

Heurística 5 - Prevenção de erros

violação 5.1 (obstáculo) - no serviço de horóscopo, quando o usuário seleciona um dos signos do zodíaco, ele é direcionado a uma página com informações sobre todos os signos, na qual, em cada um deles, é oferecido, dentre outros, o link "volta". Esse link, que pela descrição sucinta deveria permitir voltar à página anterior - página inicial do serviço de horóscopo -, em lugar disso, leva o usuário ao topo da página atual, no qual ele não teria, presumivelmente, nenhum interesse em ir; e

violação 5.2 (barreira) - na seção de meteorologia ("Tempo"), é oferecido um link externo para consultar a previsão meteorológica dos 10 dias seguintes, link que não foi completado com sucesso em algumas das ocasiões em que foi testado, ao longo da avaliação.

Heurística 8 - Design estético e minimalista

violação 8.1 (obstáculo) - em muitas das notícias são oferecidos, depois do parágrafo inicial ou lead, vários links a outras informações da mesma seção da notícia que está sendo consultada, com frequência sobre assuntos em nada relacionados com essa notícia. Esses links são apresentados no meio do texto da notícia e sem diferenciação tipográfica, identificados apenas pelo sublinhado e a cor diferente, de forma que é quase inevitável que se interrompa, momentaneamente, a leitura da mesma.

Heurística 9 - Ajuda aos usuários para reconhecer, diagnosticar e se recuperar dos erros

violação 9.1 (barreira) - no caso de uma página solicitada não encontrada, o sistema ofereceu a mensagem de erro reproduzida abaixo:

\section{Página não encontrada}

\section{http://w w w 1. folha.uol.com.br/folha/ilustra OK}

A página que você procura não existe nos servidores do UOL.

Corrija o endereço acima e tente novamente.

Cabe perguntar como o usuário - que procurou a página através de um link oferecido pelo sistema e não através da digitação de um 
determinado endereço - poderia ter os conhecimentos necessários para, seguindo as instruções do sistema, "corrigir o endereço" que não foi encontrado. O sistema parece estar sugerindo, de alguma forma, que a inexistência da página decorre de um erro do usuário, quando o oportuno seria um pedido formal de desculpas por ter oferecido a ele o acesso a um conteúdo que não se encontra disponível no sistema.

As violações 2.2, 5.2, 9.1 e 1.1 foram consideradas barreiras à interação, por impedirem a execução das tarefas desejadas pelo usuário. As violações $2.1,4.2,4.4,5.1,8.1,1.2$ e 1.3 foram consideradas obstáculos, por serem contornáveis pelo usuário. As violações restantes $3.1,4.1$ e 4.3 - foram classificadas como ruídos, por ter baixo impacto na interação do usuário com o sistema. Não foi identificada, nesse segundo caso, nenhuma violação das heurísticas 6, 7 e 10 .

A Tabela 1, abaixo, resume, de forma sintética, o número de violações encontradas nos dois sites analisados, para cada uma das dez heurísticas de Nielsen:

Tabela 1 - Resumo das violações encontradas na avaliação

\begin{tabular}{l|c|c|c}
\hline & ESTADÃO & FOLHA & TOTAL \\
\hline 1- Visibilidade do estado do sistema & 5 & 3 & 8 \\
\hline 2- Correspondência entre o sistema e o mundo real & 1 & 2 & 3 \\
\hline 3- Liberdade e controle por parte do usuário & 0 & 1 & 1 \\
\hline 4- Consistência e padrões & 4 & 4 & 8 \\
\hline 5- Prevenção de erros & 6 & 2 & 8 \\
\hline 6- Reconhecimento preferível a memorização & 0 & 0 & 0 \\
\hline 7- Flexibilidade e eficiência de uso & 0 & 0 & 0 \\
\hline 8- Design estético e minimalista & 1 & 1 & 2 \\
\hline 9- Ajuda aos usuários para reconhecer, diagnosticar e se & 0 & 1 & 1 \\
recuperar dos erros & & & \\
\hline 10- Suporte e documentação & 0 & 0 & 0 \\
\hline TOTAL & 17 & 14 & $\mathbf{3 1}$ \\
\hline
\end{tabular}

Fonte: dados da pesquisa.

\section{Considerações finais e propostas de pesquisa}

Em nenhum dos dois casos estudados, foram detectadas violações das heurísticas de usabilidade que comprometessem, de forma grave, a interação do usuário com o sistema. Foram detectadas, porém, em ambos os sites, falhas capazes de reduzir a qualidade da navegação e, consequentemente, a satisfação do usuário - um dos pilares fundamentais da usabilidade -, especialmente entre pessoas que acessam, pela primeira vez, os sites desses jornais online. A maior ocorrência de problemas se concentrou nas recomendações sobre: visibilidade do estado do sistema, consistência e padrões e prevenção de erros. 
Da concentração de problemas, mesmo que de escassa gravidade, nessas três heurísticas, desprende-se a conveniência de atentar para elas durante as fases de projeto e testes de produtos jornalísticos para a Internet, especialmente em produtos que pretendam atingir um volume e uma profundidade de conteúdos tão significativos, como os que apresentam os dois sites estudados. Os profissionais incumbidos pela definição e desenvolvimento de sites de conteúdos noticiosos, devem ter presente a importância de manter o usuário convenientemente informado do estado do sistema - em qual ponto da navegação se encontra e quais ações pode executar em cada momento -, como, também, de respeitar padrões internos de apresentação dos conteúdos, que permitam ao usuário se familiarizar tão rápido quanto possível com o site, de forma a fidelizar o visitante e aumentar o tráfego, um dos objetivos principais de um Website com fins comerciais.

Oferecer ao usuário tarefas que não podem ser completadas; utilizar diferentes padrões de formatação de conteúdos sem justificação; dificultar a visualização de conteúdos importantes para a compreensão global de um produto; ou levar o usuário a engano sobre qual será o resultado de uma determinada ação sobre o sistema -todas elas violações identificadas nos casos analisados - pode não chegar a interromper a interação homem-computador, mas, sem dúvida, deteriora a qualidade dessa interação, prejudicando a potencialidade de atrair e reter usuários. No atual cenário de acirrada competitividade entre empresas jornalísticas e de recortes nas verbas de publicidade, solucionar esses problemas de usabilidade pode não ser urgente, mas é, com certeza, recomendável.

O setor de imprensa e conteúdos informativos online apresenta especificidades e características próprias, que o convertem em terreno fértil para futuras pesquisas sobre a interação homem-computador e sobre usabilidade de Websites. Dentre elas, não é a menor a capacidade para incorporar, ao seu entorno, as últimas novidades em comunicação instantânea via Internet, bem como em criação e divulgação de conteúdos. Os desafios de usabilidade não são, assim, estáticos para os profissionais desta área de negócio e, sim, manifestamente dinâmicos. Espera-se que apareçam promissoras linhas de pesquisa, orientadas a identificar as problemáticas específicas de usabilidade, que possam vir a afetar a imprensa online, em decorrência das novas opções de comunicação multimídia que o mercado vem absorvendo. Estudos comparativos entre produtos eletrônicos de grandes corporações de comunicação e estudos que analisem a usabilidade de produtos reconhecidos como casos de sucesso em mídia online emergem, também, como propostas de pesquisa de grande interesse.

\section{Referências}

AGARWAL, R.; VENKATESH, V. Assessing a firm's web presence: a

heuristic evaluation procedure for the measurement of usability. Information Systems Research, v. 13, n. 2, p. 168-186, 2002. 
CARVALHO, A. A. A. Testes de usabilidade: exigência supérflua ou necessidade? In: CONGRESSO DA SOCIEDADE PORTUGUESA DE CIÊNCIAS DA EDUCAÇÃO, 5., 2002, Lisboa. Actas... Lisboa: Sociedade Portuguesa de Ciências da Educação, 2002. p. 235-242.

DIAS, C. Usabilidade na Web: criando portais mais acessíveis. Rio de Janeiro: Alta Books, 2003.

EIGHMEY, J.; McCORD, L. Adding value in the information age: uses and gratifications of sites on the World Wide Web. Journal of Business Research, v. 41, p.187-194, 1998.

GRAY, W. D.; SALZMAN, M. C. Damaged merchandise? A review of experiments that compare usability evaluation methods. HumanComputer Interaction, v. 13, n. 3, p. 203-261, 1998.

HERRERA-VIEDMA, E. et al. Evaluating the information quality of web sites: a methodology based on fuzzy computing with words. Journal of the American Society for Information Science and Technology, v. 57, n. 4, p. 538-549, 2006.

LAWRENCE, S.; GILES, C. L. Searching the Web: general and scientific information access. IEEE Communications Magazine, v. 37, p. 116-122, 1999.

LECEROF, A.; PATERNÒ, F. Automatic support for usability evaluation. IEEE Transactions on Software Engineering, v. 24, n. 10, p. 863-888, 1998.

LEINER, B. et al. A Brief History of the Internet. 2003. Disponivel em: <http://www.isoc.org/internet/history/brief.shtml>. Acesso em: 26 jul. 2009

NIELSEN, J.; MOLICH, R. Heuristic evaluation of user interfaces. Proc. ACM CHI'90 Conf., Seattle, EUA, 1-5 abril, p. 249-256, 1990.

PRYOR, L. The third wave of online journalism. Online Journalism Review. 2002. Disponível em: <http://www.ojr.org/ojr/future/1019174689.php>. Acesso em: 26 jul. 2009.

SHEDDEN, D. New media timeline. Poynter Online. 2010. Disponível em: <http://www.poynter.org/research/nm/timeline/>. Acesso em: 26 jul. 2009.

WINCKLER, M. A. A.; PIMENTA, M. S. Avaliação de usabilidade de sites web. In: SOCIEDADE BRASILEIRA DE COMPUTAÇÃO (SBC). (Org.). X Escola de Informática da SBC - Sul - ERI2002, 2002. 